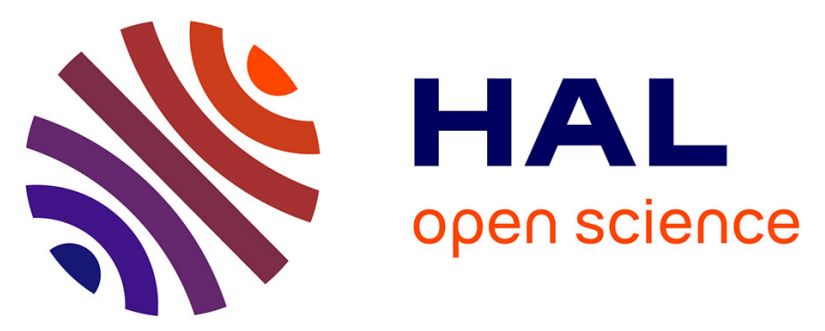

\title{
Auto-assembly of nanometer thick, water soluble layers of plasmid DNA complexed with diamines and basic amino acids on graphite: Greatest DNA protection is obtained with arginine
}

T.T. Khalil, O. Boulanouar, O. Heintz, Michel Fromm

\section{To cite this version:}

T.T. Khalil, O. Boulanouar, O. Heintz, Michel Fromm. Auto-assembly of nanometer thick, water soluble layers of plasmid DNA complexed with diamines and basic amino acids on graphite: Greatest DNA protection is obtained with arginine. Materials Science and Engineering: C, 2017, 71, pp.231 239. 10.1016/j.msec.2016.10.011 . hal-03559916

\author{
HAL Id: hal-03559916 \\ https://hal.science/hal-03559916
}

Submitted on 7 Feb 2022

HAL is a multi-disciplinary open access archive for the deposit and dissemination of scientific research documents, whether they are published or not. The documents may come from teaching and research institutions in France or abroad, or from public or private research centers.
L'archive ouverte pluridisciplinaire HAL, est destinée au dépôt et à la diffusion de documents scientifiques de niveau recherche, publiés ou non, émanant des établissements d'enseignement et de recherche français ou étrangers, des laboratoires publics ou privés. 


\section{Accepted Manuscript}

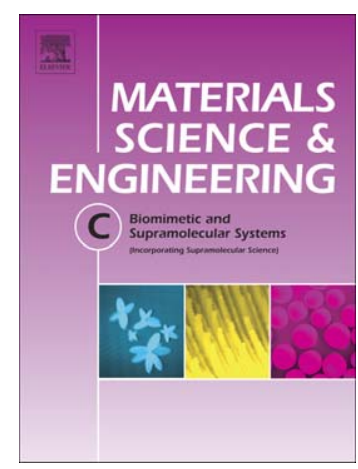

Auto-assembly of nanometer thick, water soluble layers of plasmid DNA complexed with diamines and basic amino acids on graphite: Greatest DNA protection is obtained with arginine

\section{T.T. Khalil, O. Boulanouar, O. Heintz, M. Fromm}

PII:

S0928-4931(16)31656-3

DOI:

doi: $10.1016 /$ j.msec.2016.10.011

Reference:

MSC 6980

To appear in: $\quad$ Materials Science \& Engineering $C$

Received date: 16 June 2016

Revised date: $\quad 2$ September 2016

Accepted date: 7 October 2016

Please cite this article as: T.T. Khalil, O. Boulanouar, O. Heintz, M. Fromm, Autoassembly of nanometer thick, water soluble layers of plasmid DNA complexed with diamines and basic amino acids on graphite: Greatest DNA protection is obtained with arginine, Materials Science \& Engineering C (2016), doi:10.1016/j.msec.2016.10.011

This is a PDF file of an unedited manuscript that has been accepted for publication. As a service to our customers we are providing this early version of the manuscript. The manuscript will undergo copyediting, typesetting, and review of the resulting proof before it is published in its final form. Please note that during the production process errors may be discovered which could affect the content, and all legal disclaimers that apply to the journal pertain. 


\title{
Auto-assembly of nanometer thick, water soluble layers of plasmid DNA complexed with diamines and basic amino acids on graphite: greatest DNA protection is obtained with arginine.
}

\author{
T.T. Khalil , O. Boulanouar , O. Heintz ${ }^{\S}$, M. Fromm
}

\begin{abstract}
*Université de Bourgogne Franche-Comté, UMR CNRS 6249 Chrono-Environnement, 16 Route de Gray, 25030 Besançon Cedex, France.

${ }^{\S}$ Université de Bourgogne Franche-Comté, UMR CNRS 6303Laboratoire Interdisciplinaire Carnot de Bourgogne, DTAI/Centre de micro/nano caractérisation, 9 Av. A. Savary, BP 47870 F-21078 DIJON Cedex, France
\end{abstract}

*Corresponding author: michel.fromm@univ-fcomte.fr

Tél.: (0) 33381666560

Fax.: (0) 33381666522

\begin{abstract}
We have investigated the ability of diamines as well as basic amino acids to condense DNA onto highly ordered pyrolytic graphite with minimum damage after re-dissolution in water. Based on a bibliographic survey we briefly summarize DNA binding properties with diamines as compared to basic amino acids. Thus, solutions of DNA complexed with these linkers were drop-cast in order to deposit ultra-thin layers on the surface of HOPG in the absence or presence of Tris buffer. Atomic Force Microscopy analyses showed that, at a fixed ligandDNA mixing ratio of 16 , the mean thickness of the layers can be statistically predicted to lie in the range $0-50 \mathrm{~nm}$ with a maximum standard deviation $\pm 6 \mathrm{~nm}$, using a simple linear law depending on the DNA concentration. The morphology of the layers appears to be liganddependent. While the layers containing diamines present holes, those formed in the presence of basic amino acids, except for lysine, are much more compact and dense. X-ray Photoelectron Spectroscopy measurements provide compositional information indicating that, compared to the maximum number of DNA sites to which the ligands may bind, the basic amino acids Arg and His are present in large excess. Conservation of the supercoiled topology of the DNA plasmids was studied after recovery of the complex layers in water. Remarkably, arginine has the best protection capabilities whether Tris was present or not in the initial solution.
\end{abstract}

Keywords: DNA thin film, diamines, amino acids, plasmid relaxation

\section{Introduction}

Nanometer-scale deposits of plasmid DNA (closed circular DNA double strands) which can be dissolved in water have shown considerable interest in radiobiological experiments aiming at 
deepening and refining understanding of the fundamental principles of how low-energy electrons, ions or VUV, X-rays and $\gamma$-rays interact with DNA [1-7]. In such experimental approaches it is vital to keep DNA plasmids as undamaged as possible (i.e. in their supercoiled topology) before treatment by radiation. Actually, when performing the plasmid relaxation assay, the percentages of supercoiled, open circular and linear forms were quantified; the two latter being the signatures of DNA single and double strand breaks respectively. It should be noted that in most studies which aimed at studying radiation effects at the molecular level, plasmid DNA thin films were used under the form of freezedried deposits. Sometimes however, irradiation arrangement was modified to allow humidified DNA [2-4] to be exposed to radiation under atmospheric conditions. Lyophilized plasmid DNA layers unfortunately present the disadvantage of an uneven film surface coverage and thickness [5]. In addition, with the freeze-dried layers, it is impossible to perform experiments under vacuum with so-called "pure DNA", namely with no stabilizers added to the sample before the evacuation process. Re-dissolution of the DNA plasmids in water is a sine qua non condition if a plasmid relaxation assay is to be subsequently performed. Experimentally, the presence of a chemical buffer to stabilize the plasmid DNA topology therefore appears to be a key requirement [6]. Besides, under biological conditions, nuclear DNA does not occur in free linear strands; quite the opposite, it is highly condensed and wrapped around histones [8]. Recently, we described a way to produce nanometer-scale DNA films of uniform and directly measurable thicknesses on conductive substrates of highly ordered pyrolytic graphite (HOPG) [9]. The technique employed the aliphatic diamine, 1,3-diaminopropane in its doubly protonated form $\left(\mathrm{Dap}^{2+}\right)$ at neutral $\mathrm{pH}$, to bind plasmid DNA molecules to each other. Diamines and polyamines are indeed actively involved in a considerable number of metabolic events, including DNA replication, protein synthesis, and cell growth $[10,11]$. Plasmid DNA films structured with Dap ${ }^{2+}$ as linkers have proven excellent capabilities under low energy electron $(0-20 \mathrm{eV})$ impact with the possibility, for the first time, to measure the absolute cross-section [12] for the loss of plasmid DNA supercoiled topology at the resonance energy of $10 \mathrm{eV}$ due to dissociative electron attachment (DEA). This was achieved thanks to the uniformity of the layers at the nanometer scale. Moreover, electron stimulated desorption (ESD) analyses [13] of such films have revealed that the presence of the Dap $^{2+}$ molecule in the close vicinity of the phosphate DNA moieties has a profound impact on the ESD yields of anions with notably a quasi-entire 
suppression of the $\mathrm{O}^{-}$desorption channel (generally observed when using "pure" or lyophilized DNA) in favor of the appearance of a high $\mathrm{OH}^{-}$desorption yield. This indicates that the close environment of the DNA macromolecule in more realistic biological conditions should specifically affect the way in which it responds to radiation injury. It thus appears particularly relevant to search for specific (i.e. biogenic) DNA ligands that would make it possible to produce nanometer-scaled plasmid DNA layers with the property of being soluble in water with the only severe damage due to radiation effects.

In order to tightly pack the large DNA macro-anions into the nucleus of a biological cell, life has selected to use molecular tails bearing in particular protonated amino moieties (i.e. amino acids positively charged at neutral $\mathrm{pH}$ ). In eukaryotic cell chromosomes, the basic amino acids arginine, lysine and histidine play a crucial role in packing DNA into chromatin $[14,15]$. It should be underlined that in addition to basic amino acids, polyamines are also involved in the mechanism of DNA folding-unfolding in biological cells [19] as well as stabilization of the negative charges of DNA or RNA [17].

In vitro condensation of DNA has been studied both theoretically $[18,19]$ and experimentally [20] and still remains of topical interest, especially when surface-mediated delivery of DNA is foreseen [21-23]. To condense DNA in aqueous media, at least the presence of a salt is required to neutralize DNA charges and decrease DNA-DNA poly-anion repulsion. A more sophisticated and efficient way to condense DNA consists of inducing attractive interactions between the DNA macromolecules by using multivalent cationic charged ligands (multivalent metal ions, inorganic cations, polyamines, protamines, peptides, lipids, liposomes and proteins) [15].

Using the soft adsorption (drop-casting) protocol developed for fabricating Dap-DNA layers deposited on HOPG [12], we studied the ability of aliphatic diamines of ethylene diamine (Eda), 1,4-diaminobutane (putrescine or Put), 1,5-diaminopentane (cadaverine or Cad) as well as basic amino acids histidine (His), arginine (Arg) and lysine (Lys) to condense plasmid DNA into dense layers on the surface of HOPG in the presence but also in the absence of the Tris-EDTA buffer. Atomic Force Microscopy (AFM) will be used to check and characterize the deposits formed on freshly cleaved HOPG with a defined mixing ratio $\mathrm{R}$ ( $\mathrm{R}=$ [Ligand] / [DNAphosphate]). The relationship thickness (in nanometers) of the layer versus $C_{D N A}$ at a fixed mixing ratio will be established for Dap and for Arg which gave the best deposit qualities (the cases of His, Lys, Eda, Put, Cad nevertheless are also discussed). Special attention will be paid 
to the integrity of the initial proportion of supercoiled topology of the plasmids over all the different experimental steps using gel electrophoresis measurements, including the last step that consists in recovering the plasmids in water for further analysis. The proportion of ligands (diamines and amino acids) remaining in the layers was then determined by means of X-ray Photoelectron Spectroscopy (XPS). The relationship between the type of ligand binding site and the stability of the complexes, especially maintenance of the supercoiled topology of the DNA plasmids is discussed.

\section{Materials and methods}

\subsection{Chemicals and Materials}

\subsubsection{Preparation of [DNA • ligand] complexes}

Ethylene diamine dihydrochloride ( $\geq 98 \%$ ), 1,3-diaminopropane dihydrochloride ( $\geq 98 \%), 1,4$ diaminobutane dihydrochloride ( $\geq 98 \%$ ), 1,5-diaminopentane dihydrochloride $(\geq 98 \%)$ and protonated basic amino acids of arginine hydrochloride ( $\geq 98 \%)$, histidine hydrochloride $(\geq 98 \%)$, and lysine hydrochloride ( $\geq 98 \%$ ) were all purchased from Sigma-Aldrich (France) and

kept at $4{ }^{\circ} \mathrm{C}$. Plasmid DNA (pUC21, 3266bp length and with a molecular weight of $2.13 \times 10^{6}$ Da) at an initial concentration of $1 \mathrm{mg} / \mathrm{mL}$ in water for injection (WFI) was purchased from Plasmid Factory GmbH \& Co. KG (Germany). The pUC21 mother solution was free of Tris buffer. Without further purification, stock solutions of this DNA ( $>95 \%$ supercoiled) were prepared by dilution with ultrapure water having a resistivity of $18.2 \mathrm{M} \Omega \mathrm{cm}$. The stock solutions were stored at $-20^{\circ} \mathrm{C}$. DNA concentrations were determined by measuring the absorbance at $260 \mathrm{~nm}$ using the molar extinction coefficient $\varepsilon_{260}=5.3 \times 10^{7} \mathrm{~cm}^{-1} \mathrm{M}^{-1}$. Solutions of plasmid DNA were mixed with an equal volume of a solution containing protonated ligand molecules to attain the desired ratios $R=16$ at a final DNA concentration $\left(C_{D N A}\right)$ in the range $100-500 \mathrm{ng} \cdot \mathrm{LL}^{-1}$. R, the mixing ratio, is defined as the ratio of the molar concentration of the cations to that of anionic phosphate moieties of plasmid DNA in the solution, namely $\mathrm{R}=[$ cation $] /\left[\mathrm{PO}_{4}{ }^{-}\right]$. When the Tris buffer had to be present in the solution, the pUC21 plasmid DNA mother solution was first diluted in Tris/EDTA so that the final concentration of Tris is $10 \mathrm{mM}$ Tris- $\mathrm{HCl}$ and $1 \mathrm{mM}$ EDTA, i.e. $\mathrm{pH}=7.6$. Solutions were freshly prepared before each experiment. 


\subsection{Layer Preparation and AFM investigation}

The DNA-Ligand deposits were prepared by soft adsorption: A droplet of $50 \mu \mathrm{l}$ of the [DNA Ligand] mixture was deposited onto the surface of freshly cleaved graphite (HOPG, ZYA grade, NT-MDT, NanoAndMore, France) and incubated for 15 min. Next, the surplus solution was removed using filter paper. This protocol ensures that a circular smear of constant diameter $8 \pm 1 \mathrm{~mm}$ is created on the freshly cleaved HOPG surface (it can be observed by the naked eye). Then, the surface was dried in clean air for 3 min performed.

AFM images were made using a Molecular Imaging scanning probe microscope (Agilent, USA). The topography of the surface was recorded in air, at standard temperature and pressure, with silicon nitride tips coated with aluminum (NanoAndMore, France) at a resonant frequency of $300 \mathrm{kHz}$ in the tapping mode. The way the thickness measurements were performed at the nanometer scale was presented in detail elsewhere $[9,13]$. Let us briefly recall here that, unlike the situation where the tapping mode is used to observe the layers, when working in the contact mode, the layers can be swept away leaving a tear over the entire scanned field revealing the naked HOPG surface (see Fig. 4, inset). An additional scan in the tapping mode over a greater field makes the thickness of the layer accessible to AFM measurement.

\subsection{Instruments and Methods}

Gel electrophoresis measurements were based on $1 \%$ agarose in TAE buffer at $6.7 \mathrm{~V} . \mathrm{cm}^{-1}$ for 7 minutes and $5.0 \mathrm{~V} . \mathrm{cm}^{-1}$ for 70 minutes. Both the gel and DNA-ligand mixtures were prestrained with SYBR $^{\circledR}$ Safe (Life Technologies SAS, France) (1X for gel and 20X for DNA respectively). The equivalent of one hundred nanograms of DNA was loaded per well. Gels were scanned with Bio-Rad Gel DocTM XR (Bio-Rad, France) using blue fluorescence mode at an excitation wavelength of $302 \mathrm{~nm}$. The relative amounts of each form of DNA were obtained from image analysis by Quantity One software (Bio-Rad, France).

XPS spectra were recorded with a PHI Versaprobe 5000 (PHI Sales - France, NanoAndMore) apparatus using monochromatic $\mathrm{Al} K_{\alpha} \mathrm{X}$-ray $(1486.6 \mathrm{eV})$. The average circular spot size is 200 $\mu \mathrm{m}$ diameter. High-resolution (Pass energy $=58 \mathrm{eV}$ ) $45^{\circ}$ emission angle integrated scans 
were acquired. Measurements were carried out at room temperature inside an ultra-high vacuum compartment (base pressure of $\left.8 \cdot 10^{-7} \mathrm{~Pa}\right)$. Low-energy $(<10 \mathrm{eV}$ ) electron flood and ion gun were used to neutralize the surface charge caused by photoelectron emission. The XPS data were calibrated according to the adventitious carbon 1s line (284.8 eV). A standard CASA-XPS software package (ScientaOmicron EURL, France) was used for data analysis.

\section{Results}

Before going into details with the experimental part of this work, we would like to briefly describe the main features of the linkers used in the present study (especially their chemical structure and properties) and identify the known DNA binding sites of those linkers, including Tris buffer, as exactly as possible. A brief bibliographic survey is a prerequisite for a better understanding of the differences observed, notably in terms of plasmid DNA protection all along the different steps with regard to maintaining the supercoiled topology.

\subsection{Ligands}

The molecules used to study plasmid DNA condensation and deposition properties are presented in Fig. 1.

Fig. 1. Linear diamines: ethylene diamine ( $E d a)$, 1,4-diaminobutane (putrescine or Put), 1,5-diaminopentane (cadaverine or Cad) as well as basic amino acids histidine (His), arginine (Arg) and lysine (Lys) Protonated amino groups which contribute to a bulk positive charge of the molecules at neutral $\mathrm{pH}$ are in bold blue. Due to triple resonance stabilization, the guanidinium group of the arginine (Arg) amino acid presents 3 potentially positively-charged nitrogen atoms [28].

In the aqueous environment, diamines such than Eda, Dap, Put and Cad have $\mathrm{pKa}_{1}$ and $\mathrm{pKa}_{2}$ values greater than 7 , except Eda, whose $\mathrm{pKa}_{2}$ was measured in the range $6.8-7.5$ by others $[24,25]$. Recently refined pKa calculations [26] confirm the quoted experimental data. As for the three basic amino acids, their isoelectric point (pl) is always greater than 7 [27], which implies that in aqueous media at $\mathrm{pH}=7$, all basic amino acids are ionized (zwitterionic form at neutral $\mathrm{pH}$ ). On the other hand, only arginine and lysine side-chains are ionized at neutral $\mathrm{pH}$, for the histidine side-chain, pKa=6 [28]. The latter are shown in blue in Fig. 1 for clarity. To ensure ionization of the diamines and side-chain amino groups in water, the diamines used were purchased under the form of hydrochloride salts. We may thus consider that all 
the ligands used are mostly in their doubly-ionized state for diamines with an ionized sidechain for amino acids, at neutral pH in water. Tris buffer ( $\mathrm{pKa}=8.30)$, which contains itself an amino group, is protonated at neutral pH. EDTA is also present in the chemical buffer solution but in a 10-fold lesser proportion, it is negatively charged.

\subsection{Ligand binding sites.}

\subsubsection{Diamines}

In this study, diamines Eda, Dap, Put and Cad all are considered as doubly-protonated in aqueous solution. As mentioned by Korolev and co-workers [29], diamines form only shortlived contacts with the electro-negative binding sites of DNA and do not form any structurally defined complexes. Using molecular dynamics (MD) simulations these authors have shown that diamines (Dap, Put and Cad) interact most frequently with the charged O1P and O2P phosphate atoms of the DNA backbone, Dap has the specific ability to form bridges connecting neighboring phosphate groups along the sugar-phosphate backbone of the DNA strands. Also using MD simulations, Brysont and Greenall [30] showed that electrostatic interactions concern just phosphate groups, hydrogen bonds may occur with the backbone and with DNA bases and hydrophobic interactions can result from hydrocarbon chains of diamine "binding" to non-polar parts of DNA (bases). These authors also argue that diamines may displace water from hydration sites on DNA and should therefore replace the function of DNA solvation by hydrogen bonding with amino groups. Overall, we can summarize saying that the diamines used in this study should interact similarly, i.e. showing more electrostatic DNA phosphate binding than any other type of binding.

\subsubsection{Trihydroxymethylaminomethane (Tris)}

At neutral $\mathrm{pH}$, the Tris amino group is protonated, the chemical buffer cannot therefore be considered as a simple "spectator" molecule in the presence of a DNA macro-anion. Based on free solution capillary electrophoresis measurements it has been demonstrated that most of the commonly used DNA-buffers form complexes with DNA [31] and that Tris ions might shield DNA's phosphate groups to a similar extent to sodium ions $\left(\mathrm{Na}^{+}\right)$.

\subsubsection{Basic amino acids:}

Several studies [32-36] have shown that Arg and Lys protein residues bind predominantly to DNA bases through hydrogen bonds following a multiple donor mode of interaction; they 
both display strong specificity for the guanine base (G) in DNA. Arg and Lys residues which present more than one side-chain hydrogen-bonding atom can also, to a lesser extent, produce complex interactions with multiple bases simultaneously [34,37]; i.e. with two adjacent bases presenting acceptor atoms. For specific interactions, Arg and Lys strongly favor guanine $(G)$ in hydrogen bonding, for Arg the average distribution of hydrogen bonds is for example $2.1 \%$ C, 6.5\% T, 5.1\% A, 26.1\% G and for non-specific interactions; $2.1 \%$ sugar and $58.1 \%$ phosphate [37]. Despite its apparent energetic advantage over Arg-G [34], the Lys-G interaction is observed only one third as frequently as the Arg-G interaction. Cheng and Frankel [34] have suggested that the rotational symmetry of the Lys amino group provides more ways to interact with the phosphate backbone, which therefore lowers bidentate base-specific interactions for lysine. Histidine appears to be much less reactive for both specific and non-specific interactions with DNA [37] (it should be kept in mind that in its natural form, its side chain is not ionized at neutral $\mathrm{pH}$ ). Thus, we can summarize by saying that the major interactions of basic amino acids with DNA are the following: non-specific interactions are the majority; they mainly concern the anionic phosphate sites of the DNA backbone. Specific interactions involving the three basic amino acids are of multiple natures with however a preference for the $G$ base; Arg-G interactions are the most frequent and appear under several forms (simple, bidentate, complex). Lys-G interaction is one third as frequent as Arg-G. Other things being equal, His interactions with DNA are much less frequent than those of Arg and Lys.

In order to close this overview, we present in Fig. 2 the most frequent binding sites of the diamines and amino acid Arg to DNA. For convenience purposes and to keep the figure legible, we have limited the illustrations to the most frequent binding sites of diamines and to the only basic amino acid, arginine. Arginine is in fact by far the species forming the highest percentage of specific DNA binding, except for Van der Waals bonds with the guanine base for which Lys presented a number of bonds in slight excess of those of Arg (see [37] for more details). On the other hand, Tris essentially binds to the DNA phosphate moiety and is not shown in the figure. 
Fig. 2. Two GC base-pairs with the DNA backbone are shown in blue color. The main binding sites of Arg are phosphate binding (58.1\%) and bidentate binding (26.1\% involving several forms of bidentate coupling to $\mathrm{G}$, see for example Luscombe et al [37]. for more details), the $15.8 \%$ remaining are composed of multiple bonds to other bases and to the sugar group ( $2.1 \% \mathrm{C}, 6.5 \% \mathrm{~T}, 5.1 \% \mathrm{~A}$ and 2.1 sugar). Diamines bind preferentially to the phosphate moiety of the DNA backbone with the possibility, notably for Dap, to bind two consecutive phosphate groups [29]. Blue and red dashed lines are $\mathrm{H}$-bonds; respectively intrinsic to DNA base pairing and formed between an amino acid and a base. Full red arrows indicate the possibility for diamines to bind to only one DNA strand or to connect with two different DNA helices (possibly also to connect two strands of the same closed plasmid). The red arrow which crosses the DNA double-strand indicates the special case of Dap which is able to bind two phosphate groups from opposite DNA strands across the minor groove [30], this can also be the case for Put. With only one ammonium group, Tris essentially binds to the phosphate moiety of the DNA backbone (not shown so as not to clutter the Figure).

\subsection{Thickness and composition of the layers}

Nanometer-scaled layers of DNA-Ligand complexes deposited on HOPG were prepared following the protocol presented in detail elsewhere [9]. Briefly described, the technique consists in a soft adsorption process during which a drop $(50 \mu \mathrm{l})$ of an aqueous solution of a given plasmid DNA in equilibrium with a ligand (linker) is deposited onto freshly cleaved HOPG foil itself deposited on a $1 \times 1 \mathrm{~cm}$ glass strip by using double-faced adhesive tape. After 15 minutes incubation, the residual solution was gently absorbed using filter paper and the layer dried under clean air for $3 \mathrm{~min}$. The layers formed were first analyzed using Atomic Force Microscopy (AFM) in order to check their surface roughness (planeity) and the homogeneity of the deposits on large areas (typically, circular deposits of $8 \mathrm{~mm}$ diameter were assessed by AFM over $10 \times 10$ or $5 \times 5 \mu^{2}$ areas at least at three random positions). Then, to measure the thickness we used the so-called "scratching technique" $[9,13]$. Diamines of Eda, Dap, Put and Cad were first used in order to create thin layers of DNA complexes deposited on HOPG. Typical AFM images of such layers are presented in Fig. 3. The plasmid (pUC21) DNA concentration was constant and equal to $20 \mathrm{ng} \cdot \mathrm{LL}^{-1}$ and the mixing ratio $R$ was fixed at 16 . With diamines and $R=16$ there are 16 diamines per DNA phosphate moiety in the aqueous solution drop-cast onto the graphite surface. $R=16$ was chosen because we found [9] that with increasing mixing ratios, for $R>10$, in the presence of Dap, the layer thickness measured followed a plateau-like behavior at constant DNA concentration.

Close inspection of Fig. 3 clearly shows that the nanoscale surface roughness of the samples can be separated into two trends with Eda and Cad $(n=2$ and $n=5)$ in one group and Dap and Put ( $n=3$ and $n=4)$ in the other. Holes (porosity) are indeed much greater in the deposits 
containing Eda and Cad than in those containing Dap and Put. Dap appears to be the linker which provides the most compact layers. Besides, if we compare the average thickness $Z$ $(\mathrm{nm})$ of the layers (right-handed part of Fig. 3) all layers are similar, in the range 4-6 nm.

Fig. 3. AFM images $(5 \times 5 \mu \mathrm{m})$ of layers composed of plasmid DNA complexed to Eda, Dap, Put and Cad deposited on HOPG $\left(R=16, C_{D N A}=20 \mathrm{ng} / \mu \mathrm{l}\right)$. The grey horizontal segments indicate the lines that where scanned to obtain the right-handed panel where the surface roughness is measured versus distance. Estimates of the layer thickness $(\mathrm{nm})$ remain close together, their average value being $4.75 \pm 0.96 \mathrm{~nm}$.

As reported in a previous study [9] where Dap was already used as a linker, when following our deposition protocol, the thickness of the layers formed can be controlled either by varying the plasmid DNA concentration and/or the mixing ratio R. Direct statistical measurements of the average thickness of the layers were performed at the fixed mixing ratio $R=16$ and for various plasmid concentrations $\left(C_{D N A}\right)$ in the presence and absence of Tris buffer. Experimental determinations of the layer's thicknesses were repeated statistically (at least three measurements per sample) to provide a relationship that might be used to scale layers of plasmid DNA complexed with Dap and Arg in the range 5-50 nm when deposited onto HOPG. All the results obtained are gathered in Fig. 4 and presented in Table 1.

\section{Table 1.}

Experimentally determined mean thicknesses and standard deviations for pUC21 plasmid DNA layers complexed with Dap and Arg linkers on HOPG; R $=16$.

\begin{tabular}{ccccc}
\hline $\begin{array}{c}\text { pUC21 } \\
\text { concentration }\left(\mathrm{ng} \cdot \mathrm{\mu L}^{-1}\right)\end{array}$ & Dap & Dap (TE) & $\operatorname{Arg}(\mathrm{TE})$ & $\operatorname{Arg}$ \\
\hline 100 & $10( \pm 2)$ & $3( \pm 1)$ & $3( \pm 1)$ & $7( \pm 3)$ \\
200 & $18( \pm 2)$ & $19( \pm 1)$ & $17( \pm 3)$ & $20( \pm 6)$ \\
300 & $27( \pm 3)$ & $30( \pm 2)$ & $30( \pm 2)$ & $25( \pm 5)$ \\
400 & ND & $33( \pm 3)$ & ND & $45( \pm 6)$ \\
500 & ND & $58( \pm 5)$ & ND & $50( \pm 4)$
\end{tabular}

*(TE) means that Tris-EDTA buffer was added to the solutions prior to the deposition process.

The relation $h(n m)=-0.3452+0.1008 C_{D N A}\left(R^{2}=0.9520\right)$ is the best fit to the complete data set of mean experimental layer thickness (see dashed line on Fig. 4). The general trend 
observed in the range of DNA concentrations studied is a steady increase of the thicknesses as $C_{D N A}$ increases. This relationship can if needed, serve to scale layers within a $\pm 6 \mathrm{~nm}$ precision using the linkers Dap and Arg with or without TE buffer being added, but always using a mixing ratio $\mathrm{R}=16$. Within our experimental uncertainties, especially with a standard deviation that reached a maximum of $\pm 6 \mathrm{~nm}$ for the measured mean layer thicknesses, it can be observed that Arg and Dap essentially lead to identical thicknesses within identical experimental deposition conditions and parameters. This is particularly the case at the lower plasmid DNA concentrations $\left(C_{D N A}<300\right.$ ng. $\left.\mu \mathrm{l}-1\right)$, where the dispersion of experimental data appears to be minimized. When the thickness of the layers is greater than $30 \mathrm{~nm}$, a larger dispersion can clearly be observed. As was previously shown [9] in the case of layers where Dap was associated to plasmid DNA, the presence of the Tris buffer does not dramatically modify the value of the measured thickness of the layers. We show here that this is also the case for Arg.

Fig. 4. Average thickness measurements (AFM) performed over at least three fields $(5 \times 5 \mu \mathrm{m})$ for various types of [pUC21-linker] layers (error bars represent the standard deviations). The data at $C_{D N A}=20 \mathrm{ng} \cdot \mathrm{LL}^{-1}$ are rough estimates (see text). Layers containing Dap (except the one at $C_{D N A}=20 \mathrm{ng} \cdot \mu \mathrm{L}^{-1}$ ) and $\operatorname{Arg}$ were prepared in the presence or absence of Tris-EDTA buffer (TE). The dashed line constitutes the best linear fit over all experimental points $\left(R^{2}=0.95\right)$. The inset at the bottom right is an example of the accurate AFM thickness $(h)$ measurement ("scratching technique") used and concerns the highest right-handed pale blue diamond. Except for the data set at $C_{D N A}=20 \mathrm{ng} \cdot \mu \mathrm{L}^{-1}$ all thicknesses were measured using this accurate technique.

During the course of this study, we observed that the absence of the chemical buffer Tris did not alter the organization of the [plasmid DNA - linker] film's structure when using Dap or Arg. However as shown previously [9], with Dap as a linker the presence of the Tris buffer had a strong impact on keeping a high \% of supercoiled topology when the layers have to be subsequently dissolved in water (see also the next section for more details).

Layers in which Lys and His have been used as linkers were also imaged by AFM. Accurate measurements of the thicknesses of the layers were performed only for some DNA concentrations; namely with Lys in the presence of Tris at $C_{D N A}=200$ and $C_{D N A}=300 \mathrm{ng} \cdot \mathrm{\mu L}^{-1}$ $(R=16)$; the thicknesses found were $h=8.3 \pm 4 \mathrm{~nm}$ and $h=21 \pm 3 \mathrm{~nm}$ respectively. These two thicknesses appear to be somewhat lower than those obtained when Dap or Arg were used and that is why we did not add the data concerning Lys to Fig. 4. As for His, in the presence 
of Tris, a series of three thickness measurements performed with $C_{D N A}=200 \mathrm{ng} \cdot \mu \mathrm{L}^{-1}$ and $\mathrm{R}=$ 16 provided an average value $h=17 \pm 2 \mathrm{~nm}$ in good agreement with what was measured in the presence of Dap or Arg, at the same plasmid DNA concentration.

In Fig. 5, we present two typical AFM snapshots of plasmid DNA layers were the linkers are Arg and His respectively. These pictures, when compared to those presented in Fig. 3, where the linkers are diamines, show the absence of holes in the layers and therefore the capacity of the amino acids used to provide very compact layers. It should be pointed out that, in contrast with the observations made with Arg as the linker, for the layer containing $\mathrm{His}$ a network of linked plasmids forming chains is observed all over the surface. The surfaces of layers made using the Lys linker are essentially identical to those made with Dap or Put. When auto-organizing on the surface of HOPG during the 3-D to 2-D transition the electrostatic repulsion between plasmids must be dramatically lowered by both Arg and His linkers because holes are absent at the nanometer scale. The way in which this process arises reveals some specific features of the interaction of these amino acids with plasmid DNA, which contrast with diamines. In the latter case, it is indeed likely that the interplasmid electrostatic forces that repel the macromolecules due to excess charges are at the origin of the observed holes (Fig. 3 ) in the layers.

Fig. 5. AFM images $(5 \times 5 \mu \mathrm{m})$ of layers composed of plasmid DNA complexed to (left) Arg and (right) His. On the left-hand figure, it appears that Arg is the linker which enables the highest density of the layers to be obtained. In the right-hand figure where His was used, a network of complexed plasmids, which seem to be linked together to form longer chains is clearly visible over the surface of the dense layer. It should be noted that an isolated pUC21 plasmid deposited on HOPG has a length ranging from 500 to $800 \mathrm{~nm}$, depending on its topological form. For convenience, the inset $(1 \times 1 \mu \mathrm{m})$ shows an AFM snapshot of the same plasmids (pUC21) deposited on HOPG without any linker.

To get better insight into the structuration of the layers we analyzed a series of nanometerscaled layers containing pUC21 plasmid DNA using X-ray Photoelectron Spectroscopy (XPS). $\mathrm{N}$ 1s and $\mathrm{P} 2 \mathrm{p}$ peaks relative to layers containing Arg, His and Lys mixed with pUC21 plasmid DNA are presented in Fig. 6. 
Fig. 6. XPS spectra (counts in arbitrary units, a.u.) of Arg, His and Lis complexed to pUC21 plasmid DNA and deposited on freshly cleaved $\operatorname{HOPG}\left(R=16\right.$ and $\left.C_{D N A}=200 n g . \mu L^{-1}\right)$. The left-hand spectra are relative to the XPS N1s peaks and the right-hand spectra show the XPS P2p peaks. N1s peaks are specific to the different nitrogencontaining moieties of DNA and the side-chains of the amino-acids used (see Fig. 1 and Fig. 2 for details).

XPS analyses were also performed on layers made of pUC21 plasmids complexed with Eda and Dap (spectra not displayed herein). First, the presence of phosphorus in the XPS spectra is undeniable evidence for the presence of DNA on the substrate's surface. Second, as the sequence of the pUC21 plasmid DNA used in this study is known (provided by the supplier), we can easily determine the exact ratio (N/P) $)_{\text {puc21 }}$ in pure DNA plasmids. From the complete sequence of plasmid pUC21 we get $(\mathrm{N} / \mathrm{P})_{\mathrm{pUC} 21}=3.75$ per base pair. As the XPS phosphorous signal can only result from DNA, the XPS ratio (N/P)XPs measured on layers containing linkers will thus provide an estimate of the nitrogen in excess in the analyzed layer. Therefore, XPS can provide a first estimate of the number of diamines or amino acid molecules per plasmid, or better per base pair in the analyzed layers. To explain the method let us call $\alpha$ the number of nitrogen atoms found in excess per phosphate atom $\left(\alpha=(P / N)_{X P S}-3.75\right)$ and $\beta$ the number of nitrogen atoms per ligand molecule (see Fig. 1). The number of ligand molecules per base pair (i.e. per two phosphate moieties) will thus be $2 \alpha / \beta$. The number $\gamma$ of ligand molecules which are in excess expressed in $\left(\mathrm{bp}^{-1}\right)$ is thus $(\gamma=2 \alpha / \beta-\sigma)$, where $\sigma$ corresponds to the maximum number of ligand molecules per base pair at a hypothetical complete saturation. We set thus $\sigma=2$ for diamines and $\sigma=3$ for amino acids (for more details see the section dealing with binding sites). The value $\sigma=3$ for amino acids is in fact an overestimate because it implies that the DNA plasmid would be completely composed of GC base pairs; those with which Arg contacts are the most frequent. It should also be kept in mind that the composition estimated from an XPS peak area analysis is accurate within $\sim 10 \%-20 \%$ [38] depending on the particular depth distribution of the atoms. Overall, the $\gamma$ values we will determine are thus estimates. We present, in Table 2, the results in terms of $\gamma$ values obtained by means of XPS analyses for layers containing Eda, Dap, Arg, His and Lys linkers and for which $\mathrm{R}=16$ and $\mathrm{C}_{\mathrm{DNA}}=200 \mathrm{ng} \cdot \mathrm{\mu L}^{-1}$. 


\section{Table 2.}

Experimentally determined (XPS) compositions of plasmid DNA layers complexed with Eda, Dap, Arg, His and Lys linkers on HOPG; $R=16$. TE buffer was absent in those layers during XPS experiments.

\begin{tabular}{cccccc}
\hline Ligand & Eda & Dap & Arg & His & Lys \\
\hline$(\mathrm{N} / \mathrm{P})_{\text {puc21 }}$ & 3.75 & 3.75 & 3.75 & 3.75 & 3.75 \\
$(\mathrm{~N} / \mathrm{P})_{\text {XPS }}$ & 4.63 & 5.50 & 24.51 & 14.04 & 7.87 \\
$\alpha=\mathrm{N}$ atoms in excess & 0.88 & 1.75 & 20.83 & 10.29 & 4.12 \\
$\quad($ per phosphate) & & & & & \\
$\beta=\mathrm{N}$ atoms per ligand & 2 & 2 & 4 & 3 & 2 \\
Ligand molecules $\left(\mathrm{bp}^{-1}\right)$ & 0.88 & 1.75 & 10.42 & 6.86 & 4.12 \\
$\gamma=$ Ligand molecules in excess \\
$\left(\mathrm{bp}^{-1}\right)$
\end{tabular}

It appears clearly from Table 2 that linkers (ligands) which are in excess as compared to a full saturation of the potential binding sites, are the basic amino acids Arg, His and to a much lesser extent Lys. Eda is found to be at a balance of $\sim 1$ per bp in the layers. Dap provides a quasi-complete saturation in terms of phosphate moieties of the DNA backbone ( 2 per base pair). In contrast, Arg and His appear to be in large excess in the layers. This observation therefore suggests that these two basic amino acids may have specific properties, which make it possible to incorporate large additional proportions of such ionized (positivelycharged) molecules into the plasmid DNA layers.

\subsection{Recovery of complex films in water and conservation of supercoiling}

The layers described above have the original property of being soluble in water, except, the part (first monolayer) in close contact with the HOPG surface which remains strongly linked to the HOPG, as previously reported [9] for Dap. In order to check the suitability of the layers for further experiments where they may be re-dissolved in water, we re-suspended in water layers for which the linkers were Dap, Put, Arg, His and Lys and we statistically determined the mean percentage of supercoiled topology at the end of the complete process (i.e. complexation in aqueous solution, deposition on the HOPG surface, further dissolution in water). The $\%$ of supercoiled topology is determined by means of standard agarose gel electrophoresis analyses. Eda is not used in that part of the experiments due to the poor quality of the layers it provides (high porosity); this observation by the way seems to be confirmed by its low $\gamma$-value (Table 2). On the other hand, Put was added to the set of 
ligands incorporated in the layers because it provides layers with surface properties comparable to those containing Dap (Fig. 3). In order to illustrate the role of the Tris buffer in maintaining the supercoiled topology over all the different steps; experiments were performed both in the presence and in the absence of Tris. The complete set of results is presented in Fig. 7. It clearly appears that the amino acids Arg and His, are best able to maintain the supercoiled topology of pUC21 plasmid DNA after the various steps described above have been followed; this is particularly clear when the Tris buffer is absent. Between the two amino acids, Arg is the better with only $2 \%$ loss of supercoiling in the presence of Tris buffer (we measured an average of $97 \%$ supercoiled DNA without linker in aqueous solution and $95 \%$ for the re-suspended mixture with Arg in the presence of Tris). When no buffer is added, $9 \%$ of the supercoiled topology is lost, which is rather good if additional experimental steps have to be added to the process and where the supercoiled fraction might finally be assessed. With His, in the presence of Tris, the supercoiled fraction drops down to $89 \%$ ( $8 \%$ variation) and in its absence $15 \%$ of the supercoiled fraction is lost. As may be anticipated, Put and Dap which essentially bind DNA with equivalent features (predominantly via non-specific interactions), provide comparable data. Within identical experimental conditions, Lys, even though it binds to DNA through both specific and nonspecific interactions, leads to rather high losses of supercoiling (comparably to the diamines Dap and Put).

Fig. 7. Histograms of the average \% of supercoiled topology as measured on DNA-linker mixtures obtained following dissolution of the layers in ultra-pure water. Error bars are the standard deviations determined for three measurements made on aliquots. TE stands for Tris-EDTA buffer.

\section{Discussion}

In this study, we compared the ability of the basic amino acids Arg, His and Lys with those of diamines Eda, Dap, Put and Cad to form dense, nanometer-scaled recoverable layers when complexed with plasmid DNA and deposited onto freshly cleaved surfaces of HOPG. All the species mentioned form layers with plasmid DNA which can afterwards be resuspended in water by simple washing. A bibliographic survey has shown that the basic amino acids Arg and Lys have a particular propensity to develop specific interactions (i.e. with the DNA bases) in much larger proportions than all other linkers studied, including His. 
Diamines Eda and Cad, respectively the shortest and the longest diamines used herein, produced layers with large holes when observed at the nanometer scale. This specific property is likely to be in relation with the sizes of the linkers (namely Eda and Cad); the length of latter does not match the distance that separates two consecutive phosphate moieties along the DNA backbone, or even the distance that separates two phosphates on opposite strands of a same DNA macromolecule. This results in dangling excess positive charges, likely to generate electrostatic repulsion between DNA plasmids, which will not thus, for the most part, be neutralized. Dap and Put, whose average nitrogen-nitrogen distances are close to the distance that separates two consecutive, or opposite phosphate moieties along the DNA backbone form much denser complex layers.

The case of the basic amino acids Arg, His and Lys is different in principle, due the zwitterionic character of their main chain. In addition, these three amino acids each have a particular terminal positively-charged side chain, composed of a guanidinium, an imidazole and an amino moiety when dealing respectively with Arg, His and Lys. Deposits in which Arg and His are the linkers, when analyzed by AFM, showed very high surface compacity; holes were not observed at the nanometer scale. The fact that Arg and Lys are the two linkers that form a high proportion of specific interactions with DNA [32] cannot be invoked as the sole reason to explain the protective effect observed here, and which is anyway significantly higher when using Arg than Lys. On the other hand, we have shown that Arg and His are the linkers that remain in the greatest proportions in the layers (XPS analyses of the composition of the layers). It indeed seems likely that the greater the amount of the linkers remaining in excess in a layer (so-called $\gamma$-values), the higher the protective effect against loss of supercoiling. In this regard, recent molecular dynamics simulations that concur with this last hypothesis show significant like-charge pairing of guanidinium side chains in aqueous polyarginine $[39,40]$, while such an effect is absent in aqueous poly-lysine. Interestingly too, other recent studies based on numerical simulations have reported mesoscopic structures arising from aggregates or clusters of 1,3-dialkylimidazolium-based compounds at room temperature in ionic liquids [41] but also in the aqueous phase for the special case of histidine-histidine [42]. These last observations are in turn in favor of an aggregation of histidine molecules in solution giving rise to cation-stacking clusters. Thus, based on these observations, we may argue that within an excess number of $\sim 7 \mathrm{Arg}$ per base pair and $\sim 4 \mathrm{His}$ per base pair against only $\sim 1$ for Lys and 0 for Dap and Eda, the high protective effect 
measured after dissolution of the layers in water should indeed be related to the excess of linker in the layers. Excess numbers of amino acids expressed per base pair greater than 1 are in fact unexpectedly high. Actually, in the theory of DNA condensation in solution (the counterion condensation concept) [43]; $\varphi$, namely the number of thermodynamically released $\mathrm{Na}^{+}$ions per phosphate upon ligand binding, is $\varphi \approx 0.88$ (for linear helical DNA). Thus, those large amounts of positively-charged Arg and His molecular clusters that remain in excess in the layers might be seen as a kind of charged aggregate which binds DNA and which may even allow any holes in the layers to be filled. We may thus anticipate that when complex structures of [plasmid DNA - linkers] are formed in solution, first the oppositely charged molecules neutralize each other, reducing the net charge and consequently reducing their solubility. In parallel, aggregates of Arg or His are likely to bind DNA to form complex structures which finally precipitate on the HOPG surface. This may explain the very high compaction of the two layers observed in Fig. 5, where Arg and His are the linkers and for which holes in the layers are completely absent at the nanometer scale.

Surprisingly, at a constant mixing ratio $R=16$, the dependence of the average thickness of plasmid deposits containing Arg and Dap follows within a maximum $\pm 6 \mathrm{~nm}$ deviation the same trend when plotted versus DNA concentration (in the $0-500 \mathrm{ng} \cdot \mathrm{LL}^{-1}$ concentration range). A simple fit to the experimental data provides a scaling relation that may be useful to all those who wish to use well-gauged nanometer-scaled plasmid DNA layers containing Dap or Arg deposited on HOPG with the property of being able to be re-dissolved in water. In addition, the relationship we provide seems to be invariant depending on whether the buffer Tris is present or absent. This is actually a very interesting point when dealing with electron stimulated desorption (ESD) of DNA samples [1,13], a refined technique which helps understanding and describing the fundamental aspects of radiation-induced damage of DNA. When using ESD, any additional chemical species present in the analyzed sample (layer) might create additional desorption signals and therefore might interfere and engender noisy signals. As ESD studies do not generally require further gel electrophoresis analysis, the protocol exposed herein may be extremely useful in such research areas in relation with fundamental radiobiology. Such layers, containing Tris or not, will also most probably find applications in areas where plasmid DNA deposits are used for the controlled release of therapeutic macromolecules $[44,45]$. Lastly, when present in the solution, the Tris buffer undoubtedly ensures conservation of a maximum percentage of supercoiled topology of the 
DNA plasmids after further recovering in water. Adding this buffer is thus a necessary condition for keeping high plasmid supercoiled topology when Dap, Put or Lys are used as linkers.

\section{Conclusion}

All the ligands used allowed ultra-thin and water-soluble plasmid DNA layers to be made on HOPG. Due to the fact that in diamines of Dap and Put, ammonium-ammonium separation distances are close to the distance that separates two consecutive phosphate moieties in DNA, dense layers characterized by weak porosity can be produced. In contrast, the layers obtained by using Eda and Cad exhibit large holes at the nanometer scale. Although they have different chemical structures, the basic amino acids Arg, His and Lys provide selfassembly of plasmid DNA layers with similar structural properties. Statistical measurements of the mean heights of various layers containing ligands of Dap and Arg show that the thicknesses of the layers have the same linear dependence when plotted versus DNA concentration at fixed mixing ratio $R=16$, within a $\pm 6 \mathrm{~nm}$ maximum deviation. In addition, this relation holds whether or not Tris is present in the drop-cast solution. The relation we provide may come in handy in experiments in which surface roughness and thickness have to be accurately controlled (i.e., at the nanometer scale).

Considering that the limit of ligand binding to DNA is reached for a complete saturation of the binding sites expressed per base pair, XPS data provides an estimate of the excess ligand molecules per base pair in a given layer. Only two ligands appear to be in large excess in the layers formed, namely Arg and His. The excess of ligands in the layers decreases in the following way Arg > His >> Lys > Dap > Eda. When determining the residual fraction (in \%) of supercoiled plasmid DNA present in the solution resulting from recovery of the layers in water, the following sequence is obtained Arg > His > L Lys > Dap > Put, whether Tris was present or absent from the drop-cast solution. The one-to-one relationship (for Arg, His, Lys and Dap) shows that the higher the excess of ligand molecules in the layer, the greater the protection of the supercoiled topology of the plasmid DNA throughout the various steps of the experimental procedure. Arginine provided the best protection against single-strand breakage (i.e. loss of the supercoiled topology), even in the absence of the Tris buffer, only $9 \%$ of supercoiled topology is lost. This result is consistent with the fact that in eukaryotic 
cells, arginine is the most frequent binding protein tail in histones (namely in histones $\mathrm{H} 3$ and $\mathrm{H} 4$ among the 5 main histone proteins).

Well-gauged layers (with thicknesses ranging from 10 to $50 \mathrm{~nm}$ ) of pUC21 plasmid DNA mixed with Dap have very recently been used in experiments aiming to determine the mean effective attenuation length (EAL) of low energy electrons (energies < $20 \mathrm{eV}$ ) in DNA by exposure to electrons in air [46]. Besides key experimental determinations of fundamental parameters such as EALs or damage cross-sections [12], the use of ultra-thin plasmid DNA layers such than those presented and characterized herein might also be useful in other recent research and development areas such as for example DNA thin film sensors for alpha radiation [47] or Bio-Organic Optoelectronic Devices [48].

Acknowledgments: This work was partially supported by a grant from the Iraqi embassy (Ph. D. of Dr. T. T. Khalil). We are particularly indebted to Dr. Peter Winterton (Toulouse University, France) for correcting and improving the language of the present article. 


\section{References:}

[1] Boudaiffa B, Cloutier P, Hunting DJ, Huels MA, Sanche L. Resonant formation of DNA strand breaks by low energy (3-20 eV) electrons. Science 2000;287:1658-1660.

[2] Brun E, Cloutier P, Sicard-Roselli C, Fromm M, Sanche L. Damage induced to DNA by lowenergy (0-30 eV) electrons under vacuum and atmospheric conditions. J Phys Chem $B$ 2009;113(29):10008-10013.

[3] Alizadeh E and Sanche L. The Role of Humidity and Oxygen Level on Damage to DNA Induced by Soft X-rays and Low-Energy Electrons. J Phys Chem C 2013;117(43):22445-22453.

[4] Lacombe S, Le Sech C, Esaulov VA. DNA strand breaks induced by low keV energy heavy ions. Phys Med Biol 2004;49(6):65-73.

[5] Śmiałek MA, Balog R, Jones NC, Field D, Mason NJ. Preparation of DNA films for studies under vacuum conditions The influence of cations in buffer solutions. Eur Phys J D 2010;60:31-36.

[6] Śmiałek MA, Jones NC, Balog, R, Mason NJ, Field D. The influence of the substrate temperature on the preparation of DNA films for studies under vacuum conditions. European Phys J D2011;62(2):197-203.

[7] Folkard M, Prise KM, Vojnovic B, Brocklehurst B, Michael BD. Critical energies for ssb and dsb induction in plasmid DNA by vacuum-UV photons: an arrangement for irradiating dry or hydrated DNA with monochromatic photons. Int J Radiat Biol 2000;76(6):763-771.

[8] Luscombe NM, Austin SE, Berman HM, Thornton JM. An overview of the structures of protein-DNA complexes. Genome Biol 2000;1(1):reviews001.1.

[9] Boulanouar O, Khatyr A, Herlem G, Palmino F, Sanche L, Fromm M. Soft adsorption of densely packed layers of DNA-plasmid - 1,3-diaminopropane complexes onto highly oriented pyrolitic graphite designed to erode in water. J Phys Chem C 2011;115(43):2129121298.

[10] Sakai T and Cohen S. Effects of polyamines on the structure and reactivity of tRNA. Nucleic Acids Res. Mol. Biol. 1976;17:15-43.

[11] Tabor C and Tabor H. 1,4-Diaminobutane (putrescine), spermidine, and spermine. Annu Reu Biochem 1961;45:285-306.

[12] Boulanouar O, Fromm M, Bass AD, Cloutier P, Sanche L. Absolute cross section for loss of supercoiled topology induced by $10 \mathrm{eV}$ electrons in highly uniform /DNA/1,3diaminopropane films deposited on highly ordered pyrolitic graphite. J Chem Phys 2013;139(5):055104. 
[13] Boulanouar O, Fromm M, Mavon C, Cloutier P, Sanche L. Dissociative electron attachment to DNA-diamine thin films: impact of the DNA close environment on the $\mathrm{OH}$ - and O- decay channels. J Chem Phys 2013;139(5):055101.

[14] van Holde K. E. Chromatin. New York: Springer-Verlag, 1989.

[15] Teif VB and Bohinc K. Condensed DNA: condensing the concepts. Progress in biophysics and molecular biology 2011;105(3):208-222.

[16] Larqué E, Sabater-Molina M, Zamora S. Biological significance of dietary polyamines. Nutrition 2007;23:87-95.

[17] Koculi E, Thirumalai D, Woodson SA. Counterion charge density determines the position and plasticity of RNA folding transition states. J Mol Biol 2006;359:446-454.

[18] Bloomfield VA. DNA condensation by multivalent cations. Biopolymers 1997;44:269-82.

[19] Manning GS. The molecular theory of polyelectrolyte solutions with applications to the electrostatic properties of polynucleotides. Q Rev Biophys 1978;11:179-246.

[20] Koltover I, Wagner K, Safinya CR. DNA condensation in two dimensions. PNAS 2000;97:14046-14051.

[21] Storrie $\mathrm{H}$ and Mooney DJ. Sustained delivery of plasmid DNA from polymeric scaffolds for tissue engineering. Advanced Drug Delivery Reviews 2006;58:500-514.

[22] Jewell CM and Lynn DM. Surface-mediated delivery of DNA: Cationic polymers take charge. Current Opinion in Colloid \& Interface Science 2008;13:395-402.

[23] Hujaya SD, Engbersen JFJ, Paulusse JMJ. Multilayered thin films from poly(amido amine)s and DNA. Acta Biomaterialia 2015;22:19-31.

[24] Perrin DD. Dissociation Constants of Organic Bases in Aqueous Solution; Butterworths: London, 1965.

[25] Perrin DD. Dissociation Constants of Organic Bases in Aqueous Solution, Supplement, 1972; Butterworths: London, 1972.

[26] Bryantsev VS, Diallo MS, Goddard WA. pKa calculations of aliphatic amines, diamines, and aminoamides via density functional theory with a Poisson-Boltzmann continuum solvent model. J Phys Chem A 2007;111:4422-4430.

[27] Lehninger AL, Nelson DL, Cox MM. Lehninger Principles of Biochemistry. W. H. Freeman, 2005. 
[28] Schug KA and Lindner W. Noncovalent binding between Guanidinium and anionic Groups: focus on biological- and synthetic-based Arginine/Guanidinium interactions with phosph[on]ate and sulf[on]ate residues. Chem Rev 2005;105:67-113

[29] Korolev N, Lyubartsev AP, Laaksonen A, Nordenskiöld LA. Molecular dynamics simulation study of oriented DNA with polyamine and sodium counterions: diffusion and averaged binding of water and cations. Nucleic Acids Research 2003; 31:5971-5981

[30] Brysont $\mathrm{K}$ and Greenall RJ. Binding sites of the polyamines putrescine, cadaverine, spermidine and spermine on A-and B-DNA located by simulated annealing. Journal of Biomolecular Structure and Dynamics 2000;18:393-412

[31] Stellwagen NC, Bossi A, Gelfi, C Righetti PG. DNA and buffers: are there any noninteracting, neutral pH buffers? Analytical Biochemistry 2000;287:167-175

[32] Seeman NC, Rosenberg JM, Rich A. Sequence-specific recognition of double helical nucleic acids by proteins. PNAS 1976;73:804-8

[33] Luscombe NM and Thornton JM. Protein-DNA interactions: amino acid conservation and the effects of mutations on binding specificity. J. Mol. Biol. 2002;320:991-1009

[34] Cheng $A C$ and Frankel $A D$. Ab initio interaction energies of hydrogen-bonded amino acid side chain[bond]nucleic acid base interactions. J. Am. Chem. Soc. 2004;126:434-435

[35] Lancelot G, Mayer R, Hélène C. Models of interaction between nucleic acids and proteins. Hydrogen bonding of arginine with nucleic acid bases, phosphate groups and carboxylic acids. Biochimica et Biophysica Acta 1979;564: 181-190

[36] Kono $\mathrm{H}$ and Sarai A. Structure-based prediction of DNA target sites by regulatory proteins. Protein-Struct. Func. Genet. 1999;35: 114-131

[37] Luscombe NM, Laskowski RA, Thornton JM. Amino acid-base interactions: a threedimensional analysis of protein-DNA interactions at an atomic level. Nucleic Acids Research 2001;29:2860-2874

[38] Tougaard S. Validity of automated x-ray photoelectron spectroscopy algorithm to determine the amount of substance and the depth distribution of atoms. J. Vac. Sci. Technol. A 2013;31: 031503.

[39] Vondraśěk J, Mason PE, Heyda J, Collins KD, Jungwirth PJ. The molecular origin of likecharge Arginine-Arginine pairing in water. Phys. Chem. B 2009;113(27):9041-9045

[40] Vazdar M, Vymětal J, Heyda J, Vondrášek J, Jungwirth P. Like-charge guanidinium pairing from molecular dynamics and ab initio calculations. J. Phys. Chem. A 2011;115(41):1119311201 
[41] Turton DA, Hunger J, Stoppa A, Hefter G, Thoman A, Walther M, Buchner R, Wynne K. Dynamics of imidazolium ionic liquids from a combined dielectric relaxation and optical Kerr effect study: evidence for mesoscopic aggregation. J. Am. Chem. Soc. 2009;131:1114011146

[42] Heyda J, Mason PE, Jungwirth P. Attractive interactions between side chains of Histidine-Histidine and Histidine-Arginine-based cationic dipeptides in water. J. Phys. Chem. B 2010;114 (26):8744-8749

[43] Record Jr. MT, Anderson CF, Lohman TM. Thermodynamic analysis of ion effects on the binding and conformational equilibria of proteins and nucleic acids: the roles of ion association or release, screening, and ion effects on water activity. Q. Rev. Biophys. 1978;11:103-178

[44] Yamauchi F, Kato K, Iwata H. Layer-by-layer assembly of poly(ethyleneimine) and plasmid DNA onto transparent Indium-Tin oxide electrodes for temporally and spatially specific gene transfer. Langmuir 2005;21(18):8360-8367

[45] Hujaya SD, Engbersen JFJ, Paulusse JMJ. Multilayered thin films from poly(amido amine)s and DNA. Acta Biomaterialia 2015;22:19-31

[46] Fromm $\mathrm{M}$ and Boulanouar O. Low energy electrons and ultra-soft X-rays irradiation of plasmid DNA. Technical innovations. Radiat. Chem. Phys. 2016; doi:10.1016/j.radphyschem.2016.05.025

[47] Kulkarni A, Kim B, Dugasani SR, Joshirao P, Kim JA, Vyas C, Manchanda V, Kim T, Park SH. A novel nanometric DNA thin film as a sensor for alpha radiation. Sci. Rep. 2013;3:2062

[48] Singh TB, Sariciftci NS, Grote JG. Bio-organic optoelectronic devices using DNA. Adv. Polym. Sci. 2010;223:189-212 
Fig. 1. Linear diamines: ethylene diamine (Eda), 1,4-diaminobutane (putrescine or Put), 1,5-diaminopentane (cadaverine or Cad) as well as basic amino acids histidine (His), arginine (Arg) and lysine (Lys) Protonated amino groups which contribute to a bulk positive charge of the molecules at neutral $\mathrm{pH}$ are in bold blue. Due to triple resonance stabilization, the guanidinium group of the arginine (Arg) amino acid presents 3 potentially positively-charged nitrogen atoms [28].

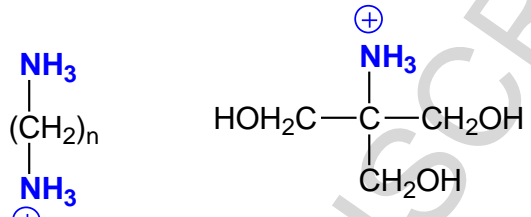

()
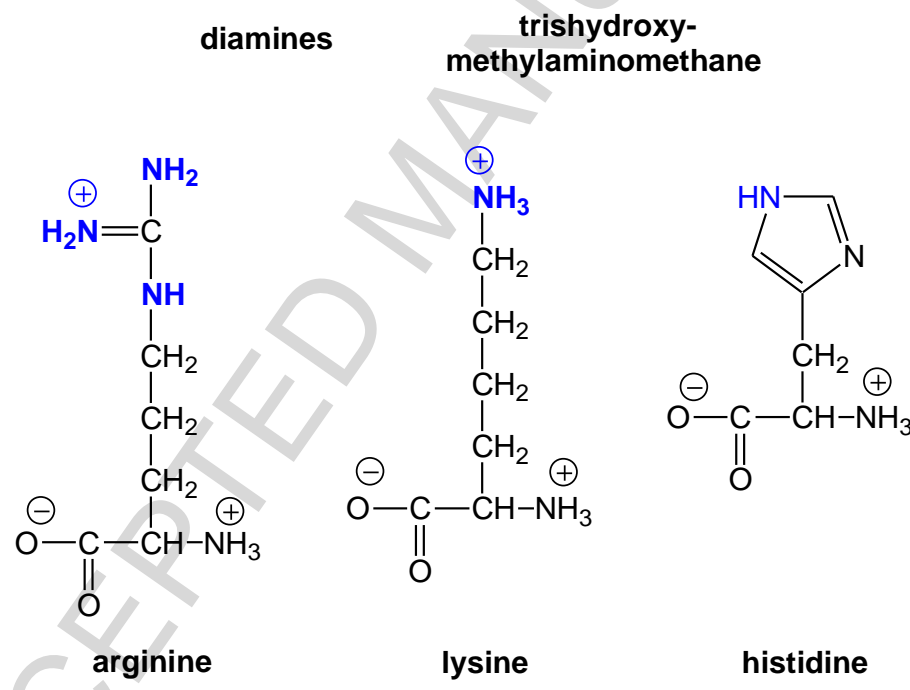

Basic amino acids 
Fig. 2. Two GC base-pairs with the DNA backbone are shown in blue color. The main binding sites of Arg are phosphate binding $(58.1 \%)$ and bidentate binding (26.1\% involving several forms of bidentate coupling to $\mathrm{G}$, see for example Luscombe et al [37]. for more details), the $15.8 \%$ remaining are composed of multiple bonds to other bases and to the sugar group (2.1\% C, 6.5\% T, 5.1\% A and 2.1 sugar). Diamines bind preferentially to the phosphate moiety of the DNA backbone with the possibility, notably for Dap, to bind two consecutive phosphate groups [29]. Blue and red dashed lines are $\mathrm{H}$-bonds; respectively intrinsic to DNA base pairing and formed between an amino acid and a base. Full red arrows indicate the possibility for diamines to bind to only one DNA strand or to connect with two different DNA helices (possibly also to connect two strands of the same closed plasmid). The red arrow which crosses the DNA double-strand indicates the special case of Dap which is able to bind two phosphate groups from opposite DNA strands across the minor groove [30], this can also be the case for Put. With only one ammonium group, Tris essentially binds to the phosphate moiety of the DNA backbone (not shown so as not to clutter the Figure).

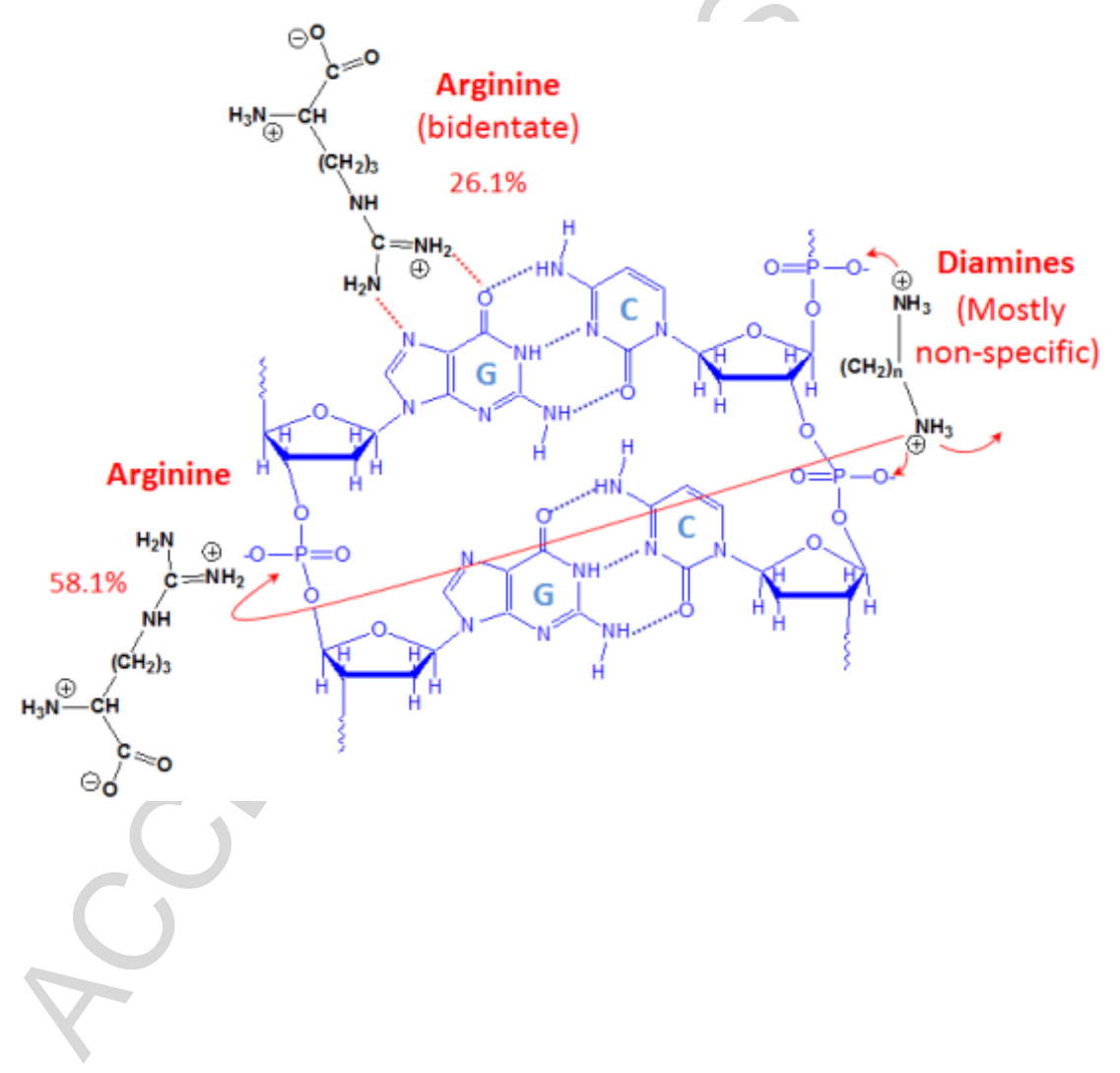


Fig. 3. AFM images $(5 \times 5 \mu \mathrm{m})$ of layers composed of plasmid DNA complexed to Eda, Dap, Put and Cad deposited on HOPG $\left(R=16, C_{D N A}=20 \mathrm{ng} / \mu \mathrm{l}\right)$. The grey horizontal segments indicate the lines that where scanned to obtain the right-handed panel where the surface roughness is measured versus distance. Estimates of the layer thickness $(\mathrm{nm})$ remain close together, their average value being $4.75 \pm 0.96 \mathrm{~nm}$.
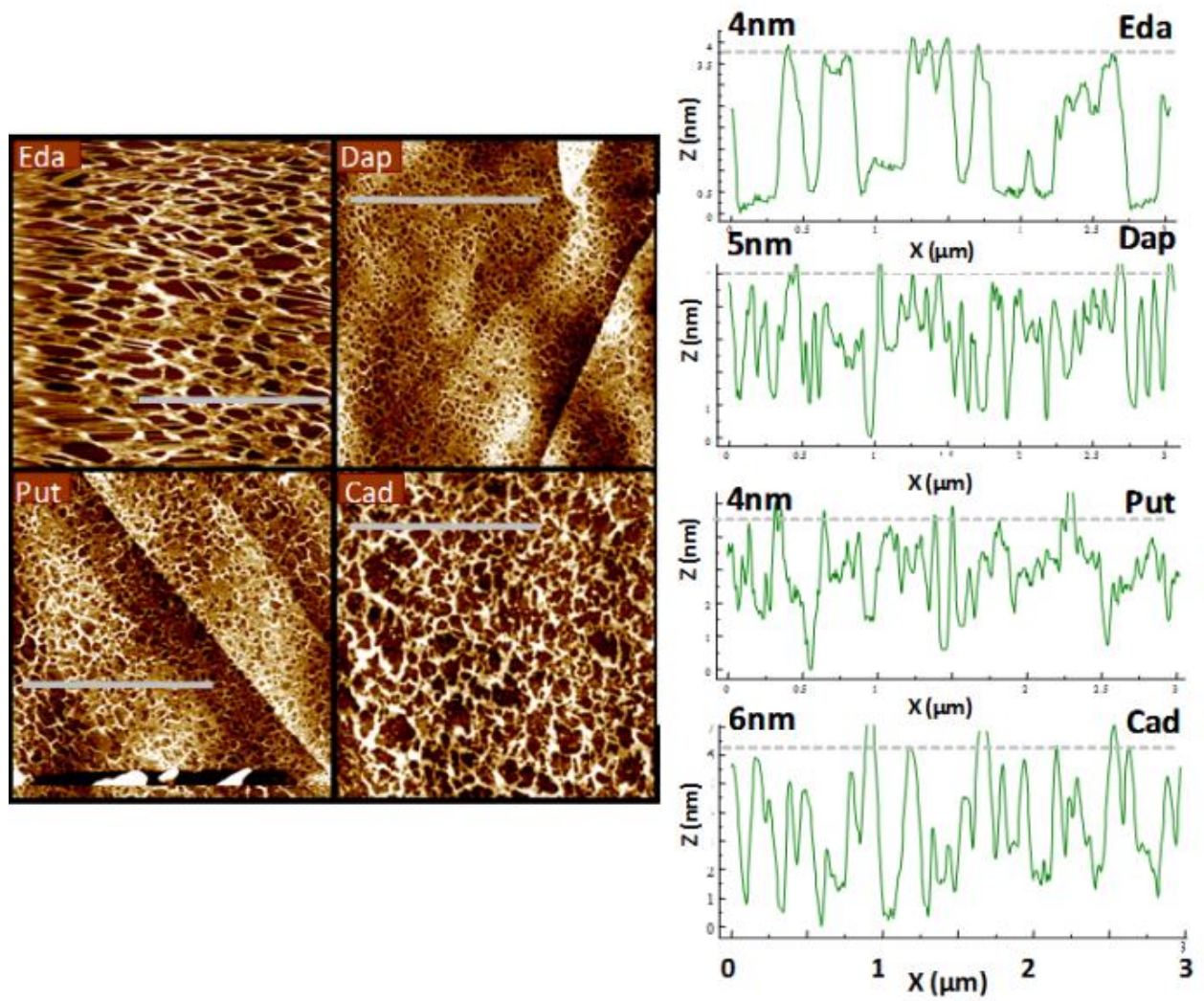
Fig. 4. Average thickness measurements (AFM) performed over at least three fields $(5 \times 5 \mu \mathrm{m})$ for various types of [pUC21-linker] layers (error bars represent the standard deviations). The data at $C_{D N A}=20 \mathrm{ng} \cdot \mathrm{LL}^{-1}$ are rough estimates (see text). Layers containing Dap (except the one at $C_{D N A}=20 \mathrm{ng} \cdot \mathrm{LL}^{-1}$ ) and $\operatorname{Arg}$ were prepared in the presence or absence of Tris-EDTA buffer (TE). The dashed line constitutes the best linear fit over all experimental points $\left(R^{2}=0.95\right)$. The inset at the bottom right is an example of the accurate AFM thickness (h) measurement ("scratching technique") used and concerns the highest right-handed pale blue diamond. Except for the data set at $C_{D N A}=20 \mathrm{ng} \cdot \mu^{-1}$ all thicknesses were measured using this accurate technique.

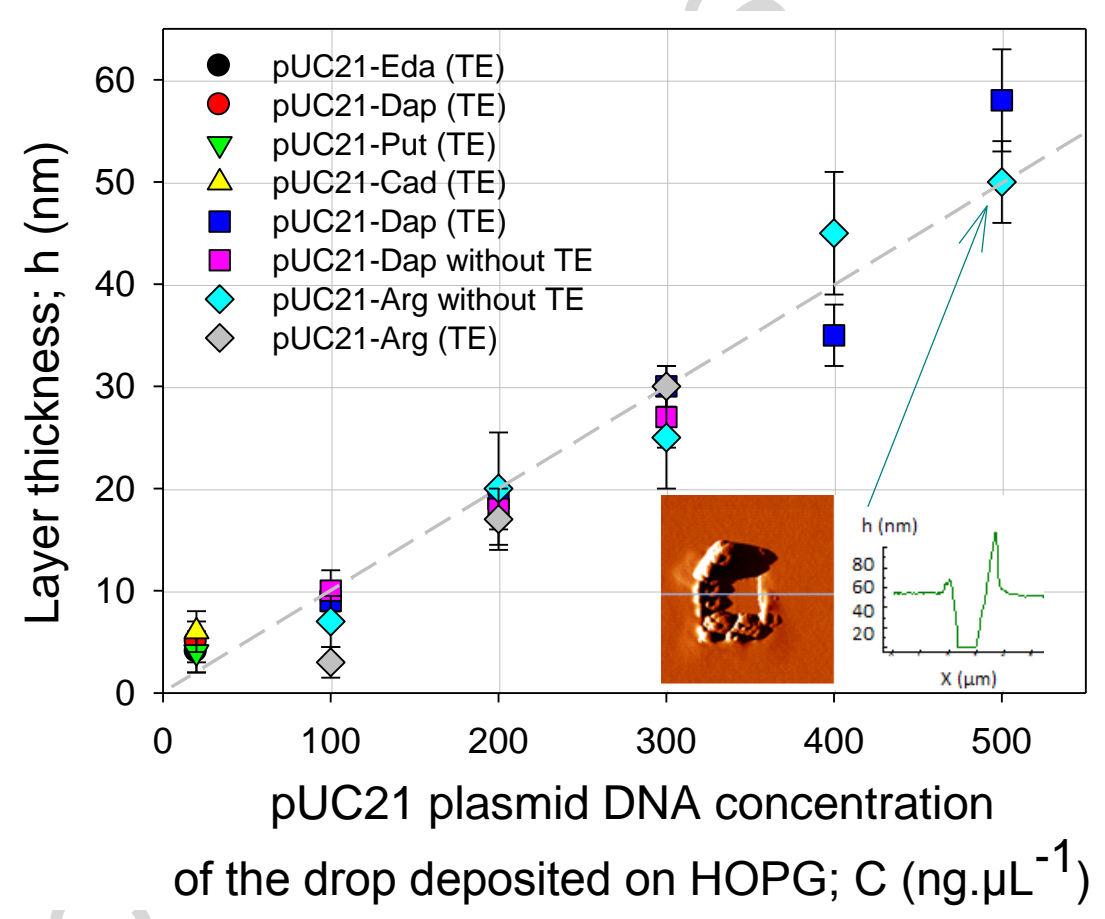


Fig. 5. AFM images $(5 \times 5 \mu \mathrm{m})$ of layers composed of plasmid DNA complexed to (left) Arg and (right) His. On the left-hand figure, it appears that Arg is the linker which enables the highest density of the layers to be obtained. In the right-hand figure where His was used, a network of complexed plasmids, which seem to be linked together to form longer chains is clearly visible over the surface of the dense layer. It should be noted that an isolated pUC21 plasmid deposited on HOPG has a length ranging from 500 to $800 \mathrm{~nm}$, depending on its topological form. For convenience, the inset $(1 \times 1 \mu \mathrm{m})$ shows an AFM snapshot of the same plasmids (pUC21) deposited on HOPG without any linker.

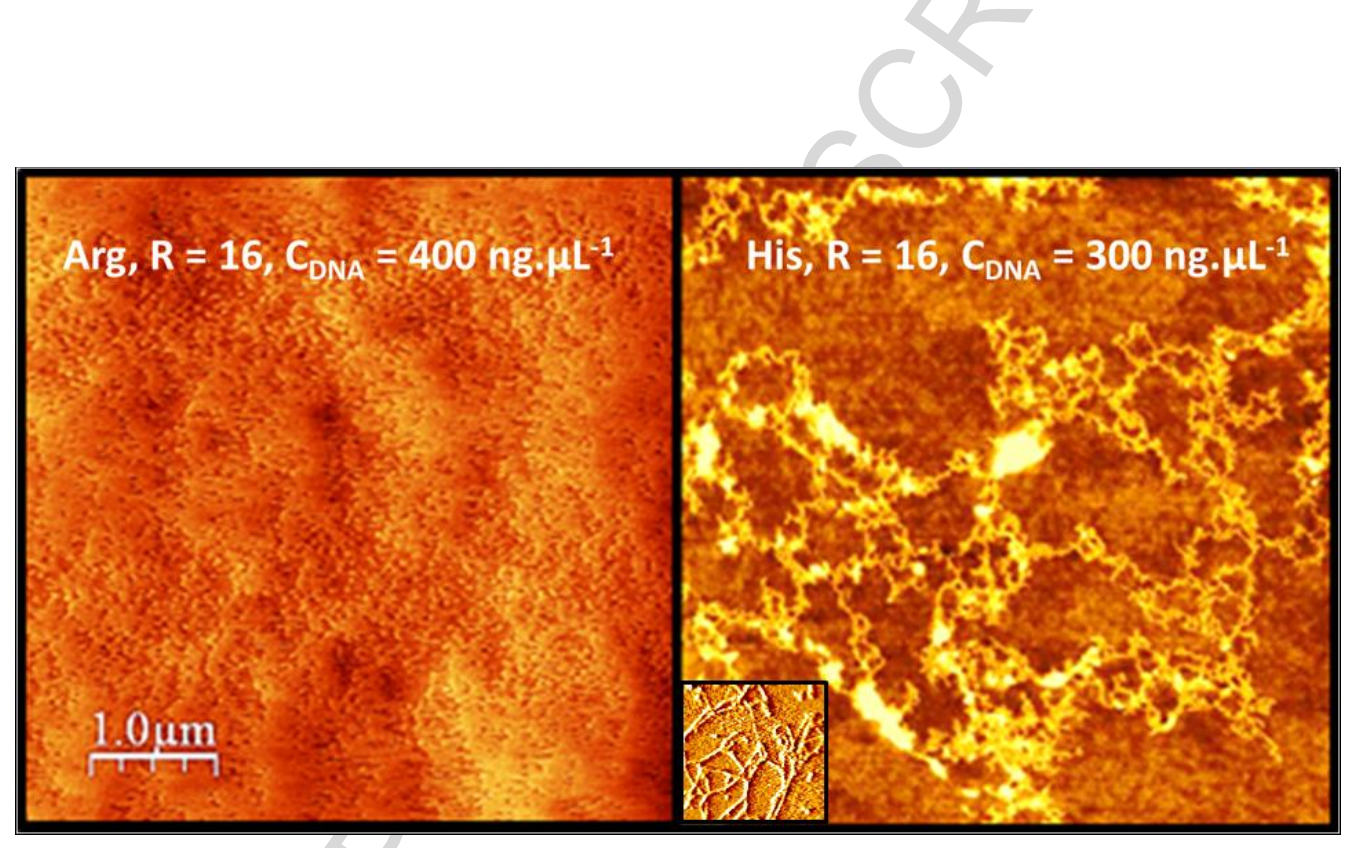


Fig. 6. XPS spectra (counts in arbitrary units, a.u.) of Arg, His and Lis complexed to pUC21 plasmid DNA and deposited on freshly cleaved $\operatorname{HOPG}\left(R=16\right.$ and $\left.C_{D N A}=200 n g . \mu L^{-1}\right)$. The left-hand spectra are relative to the XPS N1s peaks and the right-hand spectra show the XPS P2p peaks. N1s peaks are specific to the different nitrogencontaining moieties of DNA and the side-chains of the amino-acids used (see Fig. 1 and Fig. 2 for details).
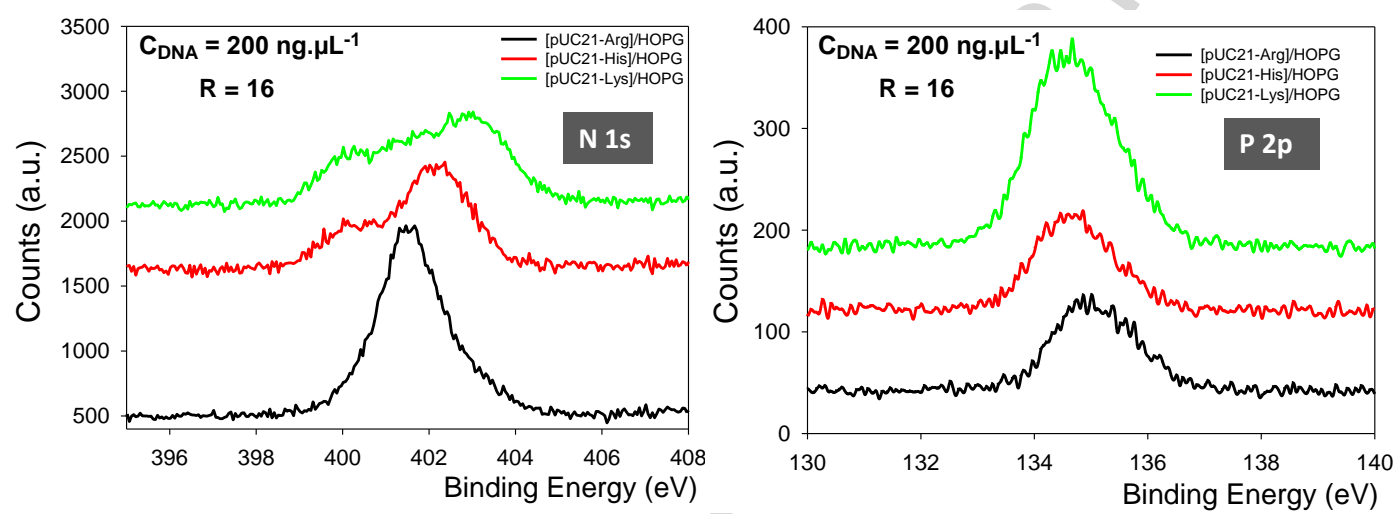
Figure 7: Histograms of the average \% of supercoiled topology as measured on DNA-linker mixtures obtained following dissolution of the layers in ultra-pure water. Error bars are the standard deviations determined for three measurements made on aliquots. TE stands for Tris-EDTA buffer.

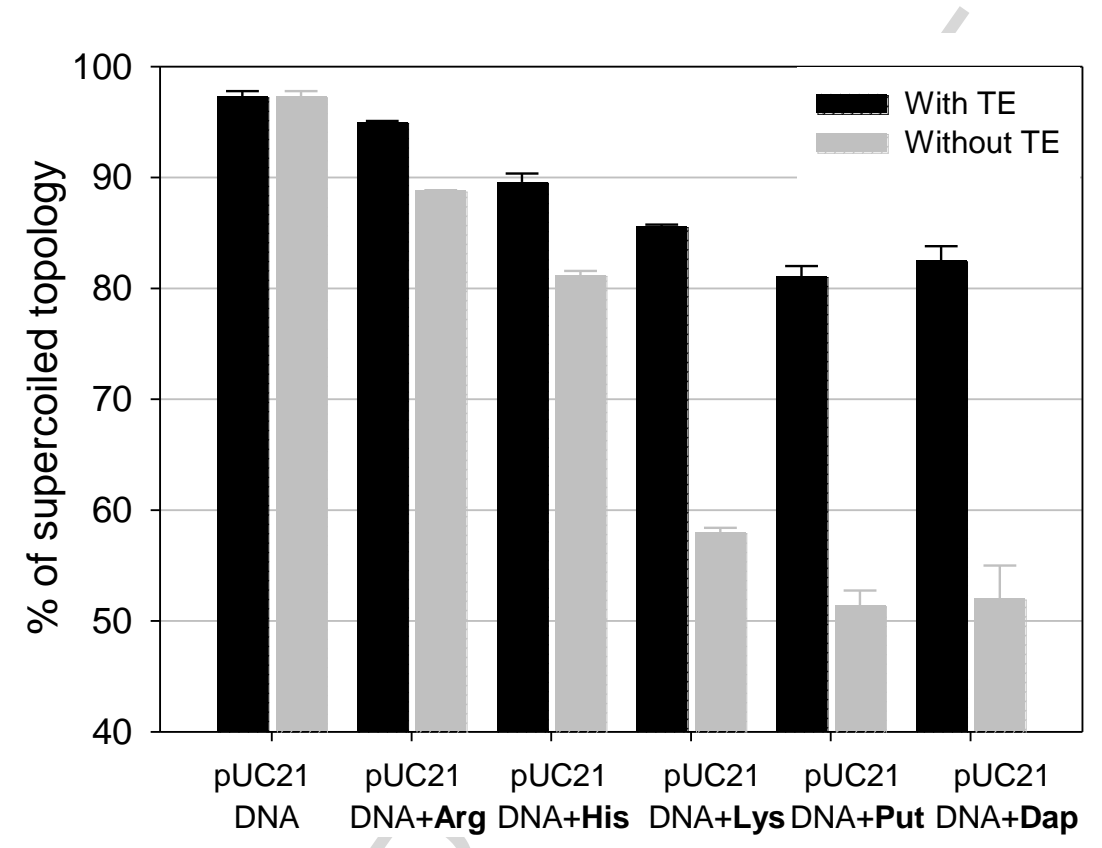




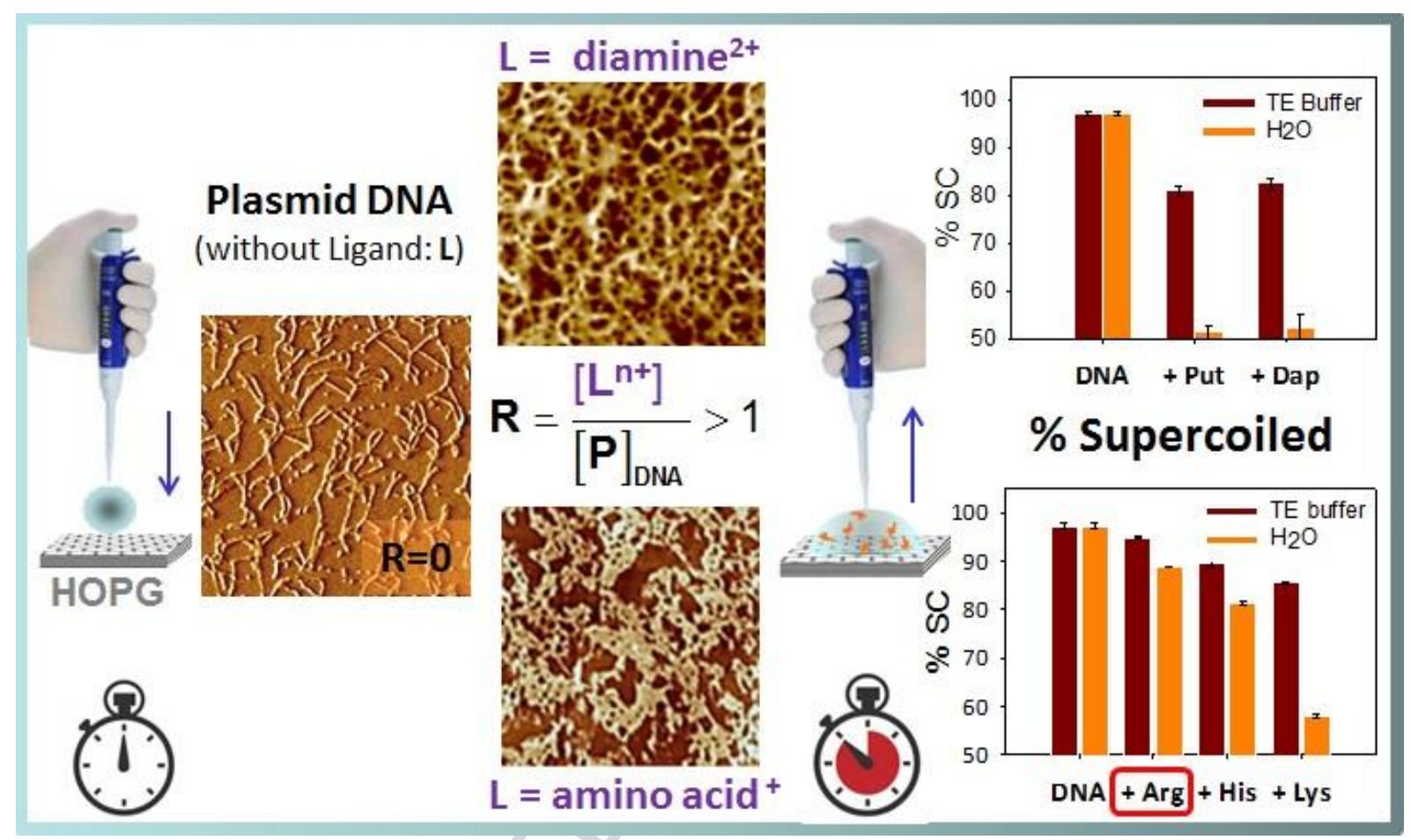

Graphical abstract 


\section{Highlights:}

- $\quad$ Characterization of nanometer scaled layers composed of pUC21 plasmid DNA

- $\quad$ Relation between nature of the ligand and structure of the layers

- $\quad$ Capacities of the ligands to protect plasmids from strand break depending on their nature 